\title{
Kode Sastra dalam Sastra Lisan Aceh Hikayat Jugi Tapa
}

\author{
Yulsafli $^{* 1}$, Burhanuddin AG ${ }^{1}$, Ismawirna ${ }^{1}$ \\ ${ }^{1}$ Program Studi Pendidikan Bahasa Indonesia, Fakultas Keguruan dan Ilmu Pendidikan, Universitas \\ Serambi Mekkah, Banda Aceh, 23249, Indonesia \\ *Email korespondensi: yulsafli@serambimekkah.ac.id ${ }^{1}$
}

Diterima 12 Agustus 2018; Disetujui 30 September 2018; Dipublikasi 31 Oktober 2018

\begin{abstract}
Jugi Tapa saga is oral literature in Sawang District. North Aceh Regency, Aceh Province. This saga tells the story of the main character named Leubee Muda. Then, Leubee Muda became a heretic because he opposed his teacher named Teungku Lhok Drien. After his heresy, he was called Jugi Tapa, who became the title of this saga. One day, his teacher asked him to deliver a book to Teungku Jambo Haji. The teacher advised him not to read the book. However, Leubee Muda violated the mandate of his teacher, he read and practiced the entire contents of the book. Because of his intelligence, in a short time, he can master all the knowledge contained in the book.To perfect his magic, he must meditate and marry one hundred beautiful women, some of whom are king's wives and daughters of dignitaries. Jugi Tapa had married eighty-eight beautiful women. Amat Banta's mother, King Sadon's wife from Kuala Diwa, was his 99th wife. He needs one more woman as his hundredth wife as a condition of perfecting his power. Before obtaining a hundred women, he could not have sex with a woman, and he continued to meditate in the palace which he made with magic. His $99^{\text {th }}$ wife was Putro Bunsu, the wife of King Sadon of the Kingdom of Kuala Diwa, having a son named Amat Banta. When Jugi Tapa brought his mother, Amat Banta was three days old. The Mother left a ring in the swing of her little son. Later that ring was the proof that he was her son she had left behind.Based on information from Bing Pho in Indonesian called Kepiting Uca (fiddler crab), Amat Banta looked for his mother to Blang Laka (in the current known as Bener Meriah Regency), where Jugi Tapa collected ninety-nine women, including Amat Banta's mother. With the help of Amat Banta 's mother who had obtained the secret of Jugi Tapa's magic from Jugi Tapa's mouth, Amat Banta managed to kill Jugi Tapa.Several messages can be taken from the story of Jugi Tapa, both as symbols, indexes, and icons. First, good deeds do not always get good replies. Therefore, every good work must be done sincerely so that we are not disappointed later on. Second, women should not be kept secret. Third, we cannot fight the teacher.
\end{abstract}

Keywords: Jugi Tapa Saga, Literature Code, Literacy, Transliteration

Abstrak: Hikayat Jugi Tapa merupakakan satra lisan yang terdapat di Kecamatan Sawang. Kabupaten Aceh Utara, Provinsi Aceh. Hikayat ini mengisahkan seorang tokoh utama yang bernama Leubee Muda. Kemudian, Leubee Muda menjadi sesat karena melawan gurunya yang bernama Teungku Lhok Drien. Setelah sesat, dia digelar Jugi Tapa, yang menjadi judul hikayat ini. Pada suatu hari, gurunya meminta kepadanya untuk mengantar sebuah kitab kepada Teungku Jambo Haji. Gurunya berpesan agar dia jangan sekali-kali membaca kitab itu. Akan tetapi, Leubee Muda melanggar amanah gurunya, dia membaca dan mengamalkan seluruh isi kitab itu. Karena kecerdasannya, dalam waktu singkat dia dapat menguasai semua ilmu yang terdapat dalam kitab tersebut. Untuk menyempurnakan kesaktiannya, dia harus bertapa dan memperistri seratus orang wanita cantik, yang sebagiannya adalah istri-istri raja dan anak orang terpandang. Jugi Tapa telah berhasil memperistrikan delapan puluh delapan wanita cantik. Ibunda Amat Banta, istri Raja Sadon dari Kuala Diwa merupakan istrinya yang ke-99. Dia memerlukan satu orang lagi wanita untuk dijadikan istrinya yang keseratus sebagai syarat 
penyempurnaan kesaktiannya. Sebelum memperoleh satus orang wanita, dia tidak boleh berhubungan kelamin dengan wanita dan dia terus bertapa di dalam kraton yang dibuatnya dengan ilmu sihir. Istrinya yang ke-99 bernama Putro Bunsu, istri Raja Sadon dari Kerajaan Kuala Diwa, mempunyai seorang putra yang bernama Amat Banta. Ketika Jugi Tapa membawa Ibundanya, Amat Banta masih berusia tiga hari. Sang Bunda meninggalkan sebilah cincin di dalam ayunan putra kecilnya. Kelak cincin itulah yang menjadi bukti bahwa itu dalah putranya yang pernah ditinggalkannya dahulu. Berdasar informasi dari Bing Pho dalam bahasa Indonesia disebut kepiting uca (fiddler crab), Amat Banta mencari ibunya ke Blang Laka (di Kabupaten Bener Meriah sekarang), tempat Jugi Tapa mengumpulkan sembilan puluh sembilan wanita, termasuk ibunda Amat Banta. Dengan bantuan ibunda yang telah memperoleh rahasia kesaktian Jugi Tapa dari mulut Jugi Tapa sendiri, Amat Banta berhasil membunuh Jugi Tapa. Ada beberapa pesan yang dapat diambil dari hikayat Jugi Tapa tersebut baik sebaigai simbol, indeks, maupun ikon. Pertama, perbuatan baik tidak selalu mendapat balasan yang baik. Oleh karena itu, setiap perbuatam baik haruslah dilakukan dengan ikhlas agar kita tidak kecewa pada kemudian hari. Kedua, pada wanita tidak boleh disimpan rahasia. Ketiga, kita tidak boleh melawan guru.

\section{Kata kunci : hikayat Jugi Tapa, kode sastra, literasi, translitrasi}

Sastra merupakan pencerminan kehidupan masyarakat. Melalui karya sastra, seorang pengarang mengungkapkan problema kehidupan yang pengarang sendiri ikut berada di dalamnya. Karya sastra menerima pengaruh dari masyarakat dan sekaligus mampu memberi pengaruh terhadap masyarakat. Bahkan seringkali masyarakat sangat menentukan nilai karya sastra yang hidup di suatu zaman, sementara sastrawan sendiri adalah anggota masyarakat yang terikat status sosial tertentu dan tidak dapat mengelak dari adanya pengaruh yang diterimanya dari lingkungan yang membesarkan sekaligus membentuknya. (Luxemburg: 1991)

Sastra pada dasarnya merupakan ciptaan manusia, sebuah kreasi bukan semata- mata sebuah imitasi. Karya sastra sebagai bentuk dan hasil sebuah pekerjaan kreatif pada hakikatnya merupakan suatu media yang mendayagunakan bahasa untuk mengungkapkan tentang kehidupan manusia. Oleh sebab itu, sebuah karya sastra pada umumnya berisi tentang permasalahan yang melingkupi kehidupan manusia. Lahirnya sastra dilatarbelakangi adanya dorongan manusia untuk mengungkapkan eksistensi dirinya. Pengungkapan eksistensi diri manusia tersebut diungkapkan dengan lisan dan tulisan. (Teeuw: 1995)

Sastra tradisional merupakan bagian dari suatu kebudayaan yang tumbuh dan berkembang di tengah-tengah masyarakat. Kehidupan sastra tradisional khususnya hikayat dapat dikatakan masih berkisar pada sastra lisan karena teks sastra dimaksud masih sangat sedikit yang dibukukan. Teks sastra lisan sebagian tersimpan di dalam ingatan orang tua, yang sekarang sudah berkurang dalam lingkungan modern.

Hikayat adalah karya sastra lama berbentuk prosa yang berisi cerita, undang- undang, dan silsilah bersifat rekaan, keagamaan, historis, biografis, atau gabungan sifat- sifat itu. Hikayat dibaca untuk pelipur lara, pembangkit semangat juang, atau sekadar untuk meramaikan pesta. (Endraswara: 2009)

Hikayat merupakan genre sastra lisan di Aceh yang paling bayak, baik dilihat dari jumlah dan keluasan cakupan isinya. Hingga saat ini belum diketahui secara pasti berapa jumlah hikayat 
Aceh yang pernah ada (pernah diciptakan atau pernah ditulis) dan yang masih ditemukan hari ini. Umumnya hikayat pada awalnya diciptakan dalam tradisi lisan, dihafal oleh penciptanya dan oleh orang-orang yang sudah terbiasa mendengarnya.

Begitulah tradisi ini berlangsung turun temurun dalam masyarakat Aceh. Upaya penulisan hikayat biasanya dilakukan oleh orang lain yang bukan penciptanya. Akan tetapi, ada beberapa hikayat yang memang ditulis sejak awal penciptaannya oleh penciptanya sendiri, meskipun kemudian sering disalin kembali dan dilakukan penambahan di sana-sini oleh orang lain. Oleh karena itu, tidaklah mengherankan jika kita menemukan beberapa pengarang dari suatu hikayat dan kadang-kadang cukup sulit bagi kita untuk mendapatkan informasi siapa pengarang asli dari hikayat tersebut. Kebiasaan ini yang berlaku dalam budaya tradisi lisan. Demikian pula halnya hikayat dalam masyarakat Aceh.

Pada saat ini sudah sangat langka orang Aceh yang dapat menghafal hikayat dan dapat pula menyampaikannya dengan baik kepada khalayak. Tambahan pula, generasi muda di Aceh pada umumnya tidak lagi menggemari hikayat, akibat daripada perubahan zaman. Dapat dipastikan bahwa apabila hikayat-hikayat yang pernah ada di Aceh akan lenyap tanpa bekas apabila tidak diaksarakan dan dikaji. Hal ini penting sebagai warisan budaya tak benda, yang merupakan khasanah kekayaan budaya Indonesia. Kajian ini menjadi tak kalah penting karena di dalam hikayat terdapat terdapat pelbagai makna yang dapat menjadi pembelajaran dalam pembentukan karakter dan jati diri generasi masa depan Indonesia.
Oleh karena itu, penulis tertarik untuk meneliti warisan budaya bangsa tersebut dengan dengan judul, "Kode Sastra dalam Sastra Lisan Aceh Hikayat Jugi Tapa."

\section{METODOLOGI PENELITIAN}

\section{Lokasi Penelitian}

Pengumpulan data yang bersumber dari responden dilakukan di Kecamatan Sawang, Kabupaten Aceh Utara, Provinsi Aceh.

\section{Metode Penelitian}

Penulis menggunakan metode deskriptifkualitatif dalam melaksanakan penelitian ini. Artinya, penulis mencatat dan merekam secara teliti ketika responden atau narasumber melantunkan hikayat Jugi Tapa. Untuk kelengkapan dan keakuratan data, penulis tidak hanya merekam ketika responden menampilkan atau melantunkan hikayat Jugi Tapa di hadapan khalayak ramai, tetapi juga menemuinya secara khusus untuk mengklasifikasi kembali data yang telah penulis rekam sebelumnya.

Metode deskriptif bertujuan untuk mencatat secara sistematis, faktual, dan akurat mengenai fakta-fakta dari daerah tertentu. Pelaksanaan metode ini mengacu pada masalah yang sedang berlangsung dan sifatnya menguraikan suatu keadaan secara sistematis, faktual, dan aktual. Dengan metode ini, data yang diperoleh dapat diolah, diklasifikasikan, dan dianailisis untuk ditarik kesimpulan yang cermat.

\section{Teknik Pengumpulan Data}

Pengumpulan data yang bersumber dari 
responden atau narasumber dilakukan di Kecamatan Sawang, Kabupaten Aceh Utara, Provinsi Aceh. Untuk kelancaran pengumpulan data dan informasi, penulis menggunakan cara pengumpulan data sebagai berikut.

\section{a. Merekam}

Peneliti merekam tuturan atau lantunan hikayat Jugi Tapa dari responden, baik daeri responden utama maupun responden pendukung.

\section{b. Wawancara}

Wawancara dilakukan untuk mengklarifikasi data yang telah diperoleh melalaui perekaman sebelumnya. Hal ini dilakukan untuk memperoleh keasihan data dan untuk memperoleh data tambahan, sehingga hasil penelitian ini benarbenar sahih. Apabila terdapat kesalahan atau kesilapan dengan adanya proses wawancara kesilapan dan kesalahan tadi akan dapat diperbaiki.

\section{c. Mengaksarakan}

Setelah proses perekaman, penulis akan mengaksarakan (menulis) data lisan yang terdapat dalam kaset rekaman ke dalam bentuk tulisan. Karya sastra Jugi Tapa yang sebelumnya hanya dapat didengar sebagai bentuk sastra lisan menjadi karya sastra yang dapat dibaca atau tertulis. Pengaksaraan di sini dilakukan dalam bahasa lokal, yaitu bahasa Aceh, dengan menggunakan aksara latin. Dengan demikian, nilai estetikanya tetap terpelihara. Pada umumnya suatu karya sastra dalam bahasa tertentu bila diterjemah ke dalam bahasa lain, nailai keindahan atau estetetisnya akan tidak akan sama persis seperti dalam bahasa asalnya. Oleh karena itu, untuk langkah pertama perekaman dilakukan dalam bahasa asalnya, yaitu bahasa Aceh.

\section{d. Menerjemahkan}

Objek penelitian ini adalah karya sastra lisan daerah Aceh. Agar karya sastra yang taktenilai harganya ini dapat dinikmati dalam skala lebih luas, penulis akan menerjemahkannya ke dalam bahasa Indonesia. Sudah barang tentu, nilai etetika suatu karya sastra akan sedikit berkurang apabila karya sastra tersebut diterjemahkan ke dalam bahasa lain. Namun demikian, penulis akan berusaha untuk melakukan penerjemahan secermat mungkin agar nilai estetika dsalam karya asal tidak banyak berkurang.

\section{Pengolahan dan Analisis Data}

Analisis data dilakukan untuk menjawab masalah penelitian. Dalam penelitian kualitatif, analisis data dapat dimulai tanpa menunggu data itu terkumpul semua. Analisis dapat dilakukan sejalan dengan tahap pengumpulan data itu (Chaer, 2007:46). Data penelitian ini diolah secara kulitatif. Pengolahan data dilakukan dalam beberapa tahap. Hal demikian perlu dilakukan untuk mendapatkan data yang lengkap. Tahap pengolahan dan analisis data dilakukan sebagai berikut.

a. Tahap pertama, menganalisis data berdasarkan teori ilmu tanda atau semiotika. Analisis ini bertujuan untuk mengetahui makna melalui kode-kode yang terdapat dalam sastra lisan Aceh hikayat Jugi Tapa.

b. Tahap kedua, mentranskrip atau menulis sastra lisan Aceh hikayat Jugi 
Tapa yang telah direkam ke dalam bentuk tulisan dengan menggunakan huruf latin. Tahap ini dimaksudkan agar dapat diperoleh data yang utuh. Dengan ditulis ke dalam bentuk tulisan dari sumbernya, diharapkan karya sastra ini tidak akan lenyap apabila penghafal hikayat ini telang meninggal. Dengan demikian, karya sastra besar ini dapat diketahui dan dibaca oleh generasi selanjutnya.

c. Tahap ketiga, menerjemahkan hikayat Jugi Tapa yang telah ditulis dalah huruf latin ke dalam bahasa Indonesia. Hal ini bertujuan agar karya sastra ini tidak hanya data dinikmati oleh penduduk lokal, yaitu masyarakat yang berbahasa ibu bahasa Aceh, tetapi juga dapat dinikmati oleh kalangan yang lebih luas, yaitu rakyat Indonesia atau siapa saja yang menguasai bahasa Indonesia atau bahasa Melayu.

\section{HASIL DAN PEMBAHASAN}

Hikayat Jugi Tapa adalah sastra lisan yang hidup di tengah-tengah masyarakat Aceh, khusunya di Kabupaten Aceh Utara dan Kabupaten Bireuen. Pada saat ini sastra lisan Aceh terancam punah, termasuk hikayatnya. Penikmatnya semakin hari semakin menyusut, seiring dengan meningalnya generasi tua. Generasi mudanya hampir tidak ada yang dapat menghafal hikayat. Lebih memprihatikan lagi bahwa penghafal-penghafal hikayat hanya tinggal satu-dua orang lagi, umur mereka sudah sangat lanjut, rata-rata berusia di atas delapan puluh tahun. Apabila mereka meninggal, maka bersamaan denga itu pula sastra lisan Aceh akan terkubur, tanpa pernah diketahui oleh generasi selanjutnya.

Hijayat Jugi Tapa dimulai dengan puja dan puji kepada Allah SWT, selawat dan salam kepada Nabi Muhammad SAW. Hal ini menunjukkan bahwa hikayat ini dikarang sewaktu Islam sudah menjadi agama resmi di Aceh.

Selanjutnya, narator memberitahukan kepada para pendengar, dia akan menceritakan sebuah cerita yang sangat bagus, yang pernah didengarnya. Dia sudah lama sekali mendengar cerita tersebut. Lalu, narator meminta kepada para pendengar untuk menyimaknya dengan baik.

Narasi dimulai ketika Leube Muda diminta oleh gurunya, Teungku Lhok Drien, untuk mengantarkan sebuah kitab pada seorang ulama yang bernama Teungku Jambo Haji di desa lain. Gurunya berpesan agar dia jangan pernah membuka atau membaca kitab tersebut.

Ternyata Leubee Muda tidak mematuhi larangan dari gurunya, dalam perjalanan dia membaca kitab itu dan menghafalnya dengan baik. Didukung oleh kecerdasannya, dalam sekejab Leubee Muda sudah menguasai ilmu yang terdapat dalam kitab tersebut. Ternyata, gurunya mengetahui bahwa dia telah membuka dan menghafal isi kitab itu. Teungku Lhok Drien sangat marah. Dia tidak pernah menyangka bahwa murid yang sangat dikasihinya itu tidak amanah. Walapun demikian, rasa sayang Teungku Lhok Drien kepada Leube Muda belum sirna. Seiring perjalanan waktu, perasaan marahnya pun sudah mulai reda. Namun, Leube muda tidak demikian, dia malah mulai mepersenda gurunya dengan cara merubah wujudnya dengan berbagai-bagai bentuk untuk menguji ilmu barunya itu. 
Kemudian terjadi pertempuran yang sangat seru antara guru dan murid dengan sama-sama berubah-rubah wujudnya dengan berbagai bentuk, seperti menjadi pohon pisang, tempat gantungan timba, pasir, air, dan burung. Pertempuran terjadi di dalam air dan di dalam tanah. Karena terdesak, Lebee Muda melarikan diri ke Blang Laka, Kecamatan Pintu Rime Gayo, Kabupaten Bener Meriah, Provinsi Aceh, dan Leubee Muda berubah nama menjadi Jugi Tapa.

Sampai pada bagian ini semuanya merupakan simbol. Secara eksplisit, narator memberi pesan kepada para pendengar bahwa kita harus menghormati guru. Jangan pernah mempermainkan dan melawan guru. Jangan seperti Leube Muda yang kemudian menjadi Jugi karena melawan gurunya. Nama Jugi dalam hikayat ini berkonotasi tidak baik: jahat peragainya, tidak tahu membalas budi, tidak memiliki empati terhadap sesama, durhaka kepada guru.

Di Blang Laka Jugi mendirikan istana dengan mantranya. Dalam istana inilah jugi menyimpan para wanita cantik yang terdiri dari anak dan istri raja-raja serta pembesar-pembesar negeri, yang diambilnya dengan kekuatan mantranya

Sebelum Jugi pergi mencari wanita-wanita cantik untuk kesempurnaan ilmunya, dia menyimpan nyawanya pada seekor burung murai di atas pohon sibonbon yang terletak ditengah-tengah rawa. Rawa-rawa itu berisi pelbagai binatang berbisa seperti naga, ular, kala jengking, dan lainlain. Semua binatang berbisa itu dibuat jugi dengan mantranya. Untuk menjaga burung itu, ditugaskannya seorang yang bernama Dalem Maddi. Jugi memantrai Dalem Maddi, sehingga dia tidak tahu jalan untuk pulang, tidak bisa ke mana-mana, dan tidak bisa berpikir dengan baik. Pekerjaannya sehari-hari hanya memancing ikan. Hasil tangkapanya itulah yang dia makan sehari-hari.

Untuk kesempurnaan ilmu dan kesaktiannya, Jugi Tapa harus memperistrikan seratus orang wanita cantik. Jugi Tapa bertapa di dalam istananya untuk menerawang keberadaan wanita-wanita cantik yang akan dijadikan istrinya. Dia sudah berhasil mengumpulkan sembilan puluh delapan orang wanita, hanya tinggal dua wanita lagi yang belum berhasil dia dapatkan. Blang Laka menjadi sepi, tidak ada lagi orang. Ada yang dibunuh, ada pula yang disihirnya menjadi berbagai macam benda, seperti batu, pohon kayu, tiang pagar istananya, dan lain-lain. Hanya tinggal seorang perumpuan, yang bernama Ni Kubayan. Perempuan tua ini ditugaskan oleh Jugi Tapa untuk menjaga dan menghibur para wanita yang dibawa dengan ilmu mantranya.

Setiap hari Jugi mencari dua orang lagi wanita untuk dibawa ke Blang Laka. Pada suatu hari dia mendengar ada seorang istri raja yang cantik jelita, bernama Putro Bunsu, istri dari Raja Sadon di Kuala Diwa. Wanita cantik ini baru melahirkan seorang anak laki-laki yang diberi nama Amat Banta, sedangkan suaminya sudah pergi berburu rusa ke dalam hutan. Raja pergi berburu rusa untk menuruti keunginan istrinya yang mengidam daging rusa. Raja pergi semasih istrinya haml tua. Sampai istrinya melahirkan Raja Sadon belum kembali.

Pada saat Putro Bunsu baru melahirkan satu hari lamanya, Jugi Tapa tiba di rumah Putro Bunsu. Dia membawa Putro Bunsu tanpa ada bantahan, karena sang Potro telah diberi mantra oleh Jugi. Walau demikian Putro sangat sedih, baru saja dia 
melihat putranya yang sangat elok rupanya, dia harus berpisah. Putro Bunsu meninggalkan sebilah cicin pada bayinya itu, dengan harapan kelak putranya besar, Putro Bunsu bisa mengenalinya dengan tanda cicin tersebut. Jugi Tapa membawa Putro Bunsu ke istananya di Blang Laka. Hari-hari Putro Bunsu dijaga oleh seorang wanita tua yang bernama Nikubayan. Nikubayan inilah yang menghibur Ptro Bunsu, terutama dengan membuat karangan bunga yang indah untuk sang Putro setiap hari.

Ketika Raja Sadon kembali dari memburu rusa, dia melihat tidak ada lagi permasurinya. Istrinya telah dibawa oleh Jugi Tapa. Hal itu diketahuinya dari kakak istrinya — dalam bahasa Aceh dipanggil Tumuda. Tidak menunggu lama, setelah meninggalkan segala pakain kebesaran dan sebilah pedang untuk sang putra, Raja Sadon pergi dengan seekor kuda untuk mencari permaisurinya ke Blang Laka pada malam hari. Di sana terletak keraton Jugi-dalam bahasa Aceh disebut kuta .

Malang sekali, Jugi mengetahui Raja Sadon sedang menuju ke tempatnya. Lalu, Jugi mengirimkan matra. Raja Sadon dan kudanya tersangkut pada sebatang pohon kelumpang (sterculia foetida) - dalam bahasa Aceh namanya bak geulumpang - karena mantra Jugi. Raja Sadon bersama kudanya menjadi dahan pohon besar itu. Sampai sekarang pada pohon tersebut masih terdapat dahan kelumpang yang menyerupai kuda yang sedang ditunggangi oleh manusia. Oleh karena itu, tempat tersebut dinamai Sawang (sekarang Kecamatan Sawang) yang berasal dari kata sawak. Kata sawak dalam bahasa Indonesia artinya sangkut; meusawak artinya tersangkut. Maksudnya, Raja Sadong tersangkut (meusawak) atas pohon kelumpang tersebut. Dari kata sawak (sangkut) itulah asal usul nama desa Sawang. Sekarang Sawang merupakan nama kecamatan di Kabupaten Aceh Utara.

Amat Banta tinggal di istana Kuala Diwa bersama bibinya ( $m a k w a)$. bibinyalah yang merawat Amat Banta. Memumasuki usia lima tahun, Amat Banta sudah pandai berbicara. Setiap hari pula dia bermain-main bersama teman-teman sebayanya. Permainan yang kerap dilakukan ialah bermain panta. Amat Banta sangat pandai bermain panta. Teman-temannya selalu kena panta dari Amat Banta, sampai mata kaki teman-temannya berdarah. Karena hal itu, teman-temannya mulai membeci Amat Banta. Di antara mereka ada yang menyuruh untuk memukul Amat Banta, serta mengatakan, "Untuk apa takut pada anak yang tidak punya ayah dan ibu." Mendengar hal itu, hati Amat Banta sangat sedih. Sambil menangis Amat Banta pulang ke rumah. Amat Banta menanyakan pada makwanya, apakah benar dia tidak mempunyai ayah dan ibu. Mendengar pertanyaan tersebut, makwanya sangat sedih, tak dapat membendung air matanya. Namun demikian, makwanya masih dapat menyakinkan Amat banta bahwa dialah ibunya, sedangkan ayahnya sudah meninggal pada waktu Amat Banta masih bayi. Amat Banta percaaya dan hatinya tidak lagi galau.

Hari-hari kemudian, Amat banta tidak lagi bermain-main bersama teman-temannya. Untuk mengisi hari-harinya, Amat Banta memancing di Krueng Ajo. Amat Banta senang dengan kegiatan barunya. Itulah yang dilakukanya setiap hari. Pada saat Banta Amat sedang asyik memancing, datang bing pho (fiddler crab), dalam bahasa Indonesia disebut kepiting uca. Sebagai mana pada umumnya, 
kepiting mempunyai sepasang tangan penjepit. Akan tetapi, kepiting ini mempunyai tangan penjepitnya kecil sebelah. Alkisah, dalam hikayat ini disebutkan bahwa tangan penjebitnya kecil sebelah karena dipukul oleh Amat Banta dengan gagang pancing.

Bing Pho memberitahukan pada Amat Banta bahwa ibunya sudah dibawa oleh Jugi Tapa ke Blang Laka. Mendengar hal itu, Amat banta sangat sangat marah, lalu dia memukul bing pho tersebut dengan gagang pancing, sehingga tangan bing pho hancur sebelah. Bing pho sangat menyesal. "Seandainya aku tahu begini akibatnya, tentu tidak akan memberitahu-kan hal tersebut kepadamu," kata bing pho pada Amat Banta. "Wahai Amat, sekarang aku sangat susah, paha kusebelah telah binasa. Baik yang aku lakukan, sagat buruk yang engkau balaskan," lanjut bing pho.

Pada bagian ini terdapat ikon, bahwa tidak semua kebaikan yang kita lakukan kepada orang lain, akan dibalas dengan kebaikan. Adakalanya kebaikan yang kita lakukan kepada orang lain dibalas dengan keburukan, seperti yang dialami oleh bing pho. Malah, akibatnya harus ditanggung oleh semua keturunan bing pho sampai sekarang. Semua bing pho memiliki tangan yang kecil sebelah, akibat nenek moyangnya dipukul oleh Banta Amat pada masa dahulu. Sampai hari ini, apabila kepiting uca ini terperogok dengan manusia, dia akan mengangkat tangan pencepitnya sebagai tanda dia minta ampun agar jangan dipukul lagi. Secara genetik, ketakutan itu diwariskan kepada anakcunya, tidak hanya secara fisik yang membuat keturunannya menjadi tangan pencepitnya kecil sebelah.

Setelah Amat Banta mendengar apa yang dikatakan oleh bing pho, dia segera pulang ke rumah dengan hati yang gundah. Sesampai di rumah, Amat Banta menanyak kebenaran kabar bing pho kepada Makwanya. Setiap hari Amat Banta menanyakan kebenaran apa yang dikatakan oleh bing pho sambil menangis. Atas pertimbangan Amat Banta sudah cukup umur dan menanyakan terus-menurus hal tersebut, maka Makwanya menceritakan kepada Amat Banta dengan sebenarnya, bahwa apa yang diberitakan oleh bing pho adalah benar.

Tidak berapa lama kemudian, Amat Banta meminta izin kepada bibinya untuk mencari Ibunda yang telah dibawa oleh Jugi Tapa, dan Ayahandanya yang tidak pernah kembali ketika mencari Ibundanya pada masa dahulu. Amat Banta pergi dengan menunggangi seekor kuda terbang - anak daripada kuda yang ditanggi ayahandanya pada masa dahulu. Setelah berhari-hari lamanya menembus awan dan rimba belantara, akhirnya Amat Banta melihat sebuah istana, yang di depannya duduk seorang wanita tua berbadan gemuk dan tidak mempunyai gigi lagi. Amat Banta mendekati wanita itu, bernama Ni Kubayan. Amat Banta dan Ni Kubayan menjadi akrab. Amat Banta bisa menumpang di rumah Ni Kubayan.

Ni Kubayan amat takut apabila Putri Bunsu mengetahui ada seorang pemuda di rumahnya. $\mathrm{Ni}$ takut Putro akan memebritahukan hal itu kepada Jugi. Jika Jugi Tapa tahu, dia akan merubah wujud Amat Banta, menjadi kayu atau batu. Oleh karena itu, Ni Kubayan selalu menyembunyikan Amat Banta di atas para ketika Ptro Bunsu mengambil karangan bunga setiap pagi di rumah Ni Kubayan.

Pada suatu pagi, Putro Bunsu melihat karangan bunga sangat bagus, tidak seperti biasanya. Sang 
Putro menaruh curiga, jangan-jangan ada tangan lain yang membuatnya. Sampai hal itu ditanyakan kepada Ni Tuha. Numun, Ni tetap mengakui, dia sendiri yang melakukannya. Putri Bunsu bertambah curiga ketika melihat sebilah cincin di jari $\mathrm{Ni}$ Kubayan. Cincin yang dipakai Ni Kubayan adalah cincin Amat Banta yang ditinggalkanya dahulu pada waktu dibawa oleh Jugi Tapa. Ketika Putro memakainyanya, cincin itu sangat pas karena itu memang cincin yang ditinggalkan pada anaknya dulu, sewaktu dijemput oleh Jugi Tapa.

Putro Bunsu semakin curiga bahwa Amat Banta disembunyikan oleh Ni Kubayan di rumah itu. Putro Mencarinya dan menemukan Amat Banta di atas para yang di sembunyikan oleh Ni di bawah belanga besar. Setelah mengetahui siapa pemuda tersebut, Putro menangis, air matanya tak tertahankan. Tidak lain, pemuda itu adalah putranya yang pernah ditinggalkan di dalam ayunan ketika berumur tiga hari.

Setelah itu, Putro Bunsu langsung pulang ke istana Jugi Tapa. Dengan bujuk rayu, Putro Bunsu menanyakan, di mana Jugi menyimpan nyawanya. Tanpa berprasangka, Jugi memberitahukan di mana Jugi menyimpan nyawanya. Tidak ada seorang pun bisa sampai ke tempat itu, karena Jugi telah memberi hikmat dan mantra, dikelilingi paya yang dalam, dan di dalamnya penuh dengan bintang berbisa. Dengan kata-kata indah, Putro Bunsu terus menanyakan, bagai mana cara bisa sampai ke tempat itu. Karena cintanya ke pada Putro Bunsu, Jugi memberitahukan segalanya. Setelah semuanya diperoleh dari Jugi Tapa, Putro Bunsu segera kembali ke rumah $\mathrm{Ni}$ Kubayan. Putro Bunsu menyerahkan segala hikmat mantra yang baru diperoleh dari Jugi Tapa dan memberitahukan segala cara kepada Amat Banta.
Berbekal semua itu, Amat Banta pun berangkat untuk mengambil nyawa Jugi yang disimpannya pada seekor burung murai di atas pohon sibon-bon, yang terletak di atas gunung di tengah payau besar yang penuh dengan binatang berbisa

Dengan segala bekal yang diberikan oleh ibunda, Amat Banta pergi untuk mengambil burung murai, tempat Jugi Tapa menyimpan nyawanya. Amat Banta harus memanjat pohon besar untuk mengambil burung itu, namun tidak mudah. Burung itu sangat lincan, melompat dari satu cabang ke cabang yang lain. Amat Banta menebang cabang phon tersebut satu persatu. Salah satu cabang pohon itu diterbangkan angin ke Samalanga. Akhirnya, Amat Banta berhasil menangkap burung murai, tempat Jugi Tapa menyimpan nyawanya.

Setelah Amat Banta dapat menangkap burung itu, dia langsung kembali ke istana Jugi. Ketika melihat di tangan Amat Banta burung itu, Jugi Tapa Amat marah. Jugi dengan segala tipu daya berusaha meminta burung tersebut dari Amat Banta. Amat Banta tidak memberikannya. Hal itu membuat Jugi semakin marah. Pada saat itulah Amat Banta membunuh burung tesebut dengan mematahkan lehernya. Bersamaan dengan itu pula Jugi menemui ajalnya.

Pada bagian ini terdapat pesan yang dapat dikategorikan sebagai indeks. Pesan tersebut disampaikan secara eksplisit oleh narator bahwa kita jangan mudah percaya kepada wanita. Pada wanita tidak bisa disampaikan rahasia. Seperti yang dialami oleh Jugi, dia mati kerena tipuan istri mudanya yang jelita. Seandainya, rahasianya itu tidak disampaikan kepada Putro Bunsu istri mudanya itu, tentu dia belum mati. 


\section{KESIMPULAN DAN SARAN}

\section{Kesimpulan}

Setelah penulis meneliti "Sastra Lisan Aceh Hikayat Jugi Tapa, peneliti dapat meremuskan beberapa kesimpulan sebagai berikut :

Hikayat Jugi Tapa merupakan sastra lisan berbentuk prosa liris yang sangat tinggi nilai estetisnya. Sebagai karya sastra yang diekspresikan dalam bahasa etnik Aceh, tentu mempunyai kekhasan tersendiri. Setiap karya sastra sangat erat hubungannya dengan bahasa yang digunakan sebagai alat pengungkapannya.

Sebagai sastra lisan, karya sastra ini sangat riskan terancam punah. Semakin hari, tokoh-tokoh penghafal hikayat ini semakin sedikit. Mereka pada umumnya generasi tua, yang pada saat ini berusia di atas tujuh puluh tahun. Apabila tidak ditulis, sudah pasti karya besar itu akan lenyap bersama tokoh penghafalnya.

Dalam hikayat Jugi Tapa ini lebih banyak ditemukan simbol, bila dibandingan dengan indeks dan ikon. Karya sastra ini dapat digolongkan sebagai karya sastra legenda, yang di dalamnya terdapat cerita asal usul suatu daerah atau tempat.

Hikayat ini berisi pesan-pesan penting yang umumnya disampaikan dengan simbol. Pesan utama, siapapun tidak boleh melanggar amanah guru, apalagi melawan guru. Akibat melanggar amanah dan melawan guru terjadi seperti apa yang dialami oleh Jugi Tapa yang merupakan tokoh uatama dalah hikayat ini. Dia menjadi sesat dengan mengamalkan ilmu hitam. Hidupnya tidak bahagia, dan akhirnya mati sia-sia.

Pesan tersebut ada pula yang disampaikan secara eksplisit seperti pada baris 1793 sampai dengan baris 2008. Pada bagian ini, pengarangnya langsung berpesan bahwa kita tidak boleh menyimpan rahasia pada wanita, buktinya adalah Jugi Tapa. Dia mati karena menyampaikan rahasianya kepada istri mudanya. Pada bagian ini, pengarang juga menyampaikan amanat secara eksplisit bahwa apabila seseorang melawan gurunya, nasibnya akhir berakhir seperti Jugi Tapa

Hikayat ini menjadi lebih menarik bagi para pendengarnya karena menceritakan asal usul berbagai tempat. Malah, diceritakan pula sebabmusabab kepiting uca (fiddler crab) tangan penjepitnya kecil sebelah. Uniknya, tempat terjadinya peristiwa (setting) terjadi pada daerah berdekatan yang dapat dikenali sampai sekarang, yakni Kuala Diwa, Sawang, Blang Laka, Samuti, Samalanga. Semua tempat itu marupakan nama desa, kecuali Sawang dan Samalanga yang sudah menjadi nama kecamatan sekaligus nama ibukota kecamatannya. Dengan demikian, dapat diperkirakan, pengarangnya berasal di sekitar kecamatan Sawang sekarang. Apalagi, semua tempat kejadian (setting) terdapat di Kecamatan Sawang, kecuali Blang Laka dan Samalanga. Secara geografis, pada masa sekarang Sawang masuk ke dalam wilayah Kabupaten Aceh Utara, Blang Laka masuk dalam wilayah Kabupaten Bener Meriah, dan Samalanga masuk ke dalam wilayah Kabupaten Bireuen. Hal terebut menunjukkan bahwa tempat terjadinya peristiwa berada pada daerah yang berdekatan.

Indeks terdapat berapa bagian, seperti cincin yang ditinggalkan oleh Putro Bunsu kepada Amat Banta sewaktu dia dijemput oleh Jugi Tapa. Cincin itu sangat berguna ketika Amat Banta sudah dewasa. 
Cincin itulah yang menjadi petunjuk kuat bahwa lelaki muda itu adalah putranya yang pernah dia tinggalkan dahulu sewaktu masih berumur tiga hari di dalam ayunan. Cincin itu lebih berharga dari seribu kata-kata. Tidak ada sedikitpun syak wasangka lagi di dalam hati sang ibunda Amat Banta bahwa itu adalah darah dagingnya yang pernah dia tinggalkannya ketika masih bayi.

Ikon dalam hikayat ini terdapat pada bing pho atau kepiting uca (fiddler crab). Pada bagian ini tedapat pesan yang sangat dalam. Bing pho menjadi ikon bahwa perbuatan baik tidak selalu mendapat balasan yang setimpal, malah bisa terjadi seperti apa yang dialami oleh bing pho. Pada masa sebelumnya bing pho memiliki sepasang tangan penjepit yang sama besar. Karena perberbuatan baik yang dilakukannya, membat tangannya kecil sebelah. Ironisnya, pahanya yang cacat itu terwarisi pada generasinya sampai ke akhir zaman. Gara-gara dia memberitahukan kepada Amat Banta bahwa ibundanya (ibu Amat Banta) telah dibawa oleh Jugi Tapa ke Blang Laka.

Bing pho tidak hanya mewariskan kecacatan fisisik kepada keturunannya, tetapi juga mewariskan genetik. Bing pho atau kepiting uca sangat takut kepada manusia. Apabila tanpa sengaja bersua dengan manusia, kepiting itu akan mengangkat kedua tangannya, seperti meminta ampun agar jangan dipukul lagi, dan dia akan lari bersembunyi di dalam lubang tanah.

Ikon ini sangat luar biasa. Pengarang dapat mencari analogi untu mendeskripsikan bahwa perbuatan yang baik tidak selalu mendapat balasan yang baik pula. Contohnya bing pho itu. Dia tidak hanya meneri akibat dari perbuatan baiknya seorang diri, tetapi keturunannya harus menanggung akibat dari perbuatan baik yang pernah dilakukan oleh nenek moyangnya pada zaman dahulu. Dengan ikon ini, pengarang mengamanatkan bahwa apabila kita berbuat baik harus ikhlas, jangan mengharapkan balasan yang baik pula, apabila kita tidak mau kecewa pada kemudian hari. Apabila kita berbuat baik, tetapi dibalas dengan keburukan, belumlah seberapa, bila dibandingkan dengan apa yang dialami oleh bing pho atau kepting uca (fiddler crab).

\section{Saran}

Sehubungan dengan penelitian ini, penulis memiliki beberapa saran sebagai berikut:

Pertama, hikayat Jugi Tapa memiliki nilai estetis yang tinggi. Hikayat ini berbentuk prosa liris yang tergolong ke dalam jenis legenda.

Kedua, Sastra lisan hikayat Jugi Tapa memiliki pesan atau amanat yang sangat penting sebagai bagian dari pendidikan karakter dan kearifan lokal bagi generasi muda sebagai pewaris bangsa.

Ketiga, Sastra lisan hikayat di Aceh teracam punah. Oleh karena itu, sangat penting karya sastra ini diteliti dan didokumentasikan agar karya ini dapat dibaca oleh generasi yang akan datang.

Keempat, penulis mengharapkan kepada pemerintah agar dapat menyelamatkan sastra lisan hikayat dengan menyediakan dana penenelitian dan menerbitkan luaran hasil penelitian dalam bentuk buku. Buku-buku tersebut dapat disebarkan ke perpustakaan-perpustakaan yang ada di Aceh maupun di luar Aceh.

Kelima, penulis mengharapkan sastra lisan hikayat dapat dijadikan muatan lokal di sekolahsekolah sebagai bagian dari pendidikan karakter dan kearifan lokal. Hal tersebut juga menjadi penting 
untuk menyelamat bahasa dan sastra Aceh dan sebagai pembelajaran yang bagus bagi generasi bangsa.

Keenam, penulis mengharapakan kepada masyarakat Aceh agar dapat menjadikan sastra lisan hikayat sebagai salah satu sarana pendidikan dan hiburan bagi puta-putrinya di lingkungan keluarga. Hal ini sangat berguna dalam pembetukan karakter anak dan juga berfungsi sebagai sarana pewarisan kearifan lokal (lokal wisdom).

\section{DAFTAR PUSTAKA}

Aliana, Zainul Arifin. At.al. (1997). Ekspresi Semiotik: Tokoh Mitos dan Legendaris dalam Tutur Sastra Nusantara di Sumatera Selatan. Jakarta: Pusat Pembinaan dan Pengembangan Bahasa.

Barthes, Roland. (1996). Unsur-Unsur Semiologi: Langua dan Parolell dalam Panuti Sudjiman dan Aart van Zoest (ed). Serba-Serbi Semiotika. Jakarta: Gramedia Pustaka Utama.

Endraswara, Suwardi. (2009). Metodologi Penelitian Folklor. Yogyakarta: Media Presindo.

Eagleton, Terry. (2006). Teori Sastra: Sebuah Pengantar Koperhensif. (Terjemahan Harfiah Widyawati). Yogyakarta: Jalasutra.

Husin, S. Jaafar. (1995). Penelitian Sastra: Metodologi dan Penerapan Teori. Kuala Lumpur: Dewan Bahasa dan Pustaka.

Luxemburg, Jan Van. Mike Bal, Willem G. Weststeijn. (1991). Tentang Sastra. Jakarta: Intermasa.
Siswanto, Wahyudi. (2008). Penganar Teori Sastra. Jakarta: Grasindo.

Sudjiman, Panuti dan Aart van Zoest (ed). (1996). Seba-Serbi Semiotika. Jakarta: Gramedia Pustaka Uama

Muradi, Supardy (ed). (1990). Kesusastraan daripada Perspektif Semiotika. Kuala Lumpur: Dewan Bahasa dan Pustaka.

Sebeok, Thomas A., (1994). An Introduction to Semiotic. London: Pinter Publis

Teeuw, A., (1995). Sastera dan Ilmu Sastera: Pengantar Teori Sastera. Kuala Lumpur: Dewan Bahasa dan Pustaka. . (1994). Indonesia antara Kelisanan dan Keberaksaraaan. Jakarta: Pustaka Jaya.

Trabaut, Jurgen. (1996). Dasar-Dasar Semiotik (Elemente der Semiotic). Terjemahan Sally Pattinasrany). Jakarta: Pusat Pembinaan dan Pengembangan Bahasa.

Winner, Irene Portis dan Jean Umiker Sebeok (ed). 1979. Semiotics of Culture. New York: Mouton Publishers.

Zoest, Aart van. 1996. Interpretasi dan Semiotikall, dalam Panuti Sudjiman (ed). Serba-Serbi Semiotika. Jakarta: Gramedia Pustaka Utama.

- How to cite this paper :

Yulsafli, Y., AG, B., \& Ismawirna, I. (2018). Kode Sastra dalam Sastra Lisan Aceh Hikayat Jugi Tapa. Jurnal Humaniora, 2(2), 118-129. 